Article

\title{
Comparative Studies on Two Types of OSB Boards Obtained from Mixed Resinous and Fast-growing Hard Wood
}

\author{
Aurel Lunguleasa ${ }^{1, *}$, Adela-Eliza Dumitrascu ${ }^{2}(\mathbb{D})$ and Valentina-Doina Ciobanu ${ }^{3}$ \\ 1 Department of Wood Processing and Design of Wood products, Faculty of Wood Engineering, \\ Transilvania University of Brasov, 1 Universitatii, 500068 Brasov, Romania \\ 2 Department of Manufacturing Engineering, Transilvania University of Brasov, Mihai Viteazul, \\ 500174 Brasov, Romania; dumitrascu_a@unitbv.ro \\ 3 Department of Silviculture and Forest Engineering, Transilvania University of Brasov, Sirul Beethoven, \\ 500123 Brasov, Romania; ciobanudv@unitbv.ro \\ * Correspondence: lunga@unitbv.ro
}

Received: 2 September 2020; Accepted: 17 September 2020; Published: 23 September 2020

Featured Application: The research carried out in this paper has an applicative role in the field of oriented strand board (OSB) manufacturing in the fields of both raw material recipes and their properties. In the field of raw material recipes, the paper recommends putting an increased emphasis on fast-growing deciduous species, which can replace a good part of increasingly expensive and hard-to-find resinous wood. In the field of the mechanical strength properties of OSBs, an optimum density of $714-740 \mathrm{~kg} / \mathrm{m}^{3}$ has been found to condition high strength without unjustifiably increasing their density.

\begin{abstract}
The paper aims to compare the oriented strand boards (OSBs) made in the laboratory from a mixture of softwood species to those made from hardwood species, followed by their comparison to European and industry standards. In this regard, the main properties of the panels made in the laboratory were determined, including density, absorption, and swelling in thickness, modulus of elasticity, modulus of rupture, and internal bond. The analysis of the properties of swelling $(24 \mathrm{~h})$ and absorption $(24 \mathrm{~h})$ revealed that the mixture of softwood species was slightly better thanthe hardwood one. It was also shown that the panels manufactured from the mixture of hardwood species had better mechanical properties than those made of the softwood mixture (modulus of rupture $(\mathrm{MOR})=43.48 \mathrm{~N} / \mathrm{mm}^{2}$, modulus of elasticity $(\mathrm{MOE})=7253 \mathrm{~N} / \mathrm{mm}$, and internal bond $(\mathrm{IB})=1.57 \mathrm{~N} / \mathrm{mm}^{2}$ ). Additionally, the comparative analysis of properties indicates that the density is highly significant in determining the MOE values of the OSBs. This will allow softwood speciestobe replaced with other species of soft and fast-growing deciduous trees such as willow, birch, and poplar in the manufacture of oriented strand boards.
\end{abstract}

Keywords: oriented strand boards (OSBs); fast-growing species, modulus of rupture (MOR); modulus of elasticity (MOE); internal bond (IB); swelling (S); water absorption (A)

\section{Introduction}

Oriented strands boards (OSBs) are increasingly sought after on the construction materials market due to its excellent properties, especially due to the increasingly competitive price. As a composite material, these boards have wood chips as their matrix and adhesives as reinforcement. European standards in the field of OSBs [1,2] classify them according to the field of use as indoor boards (OSB/1 and OSB/2) and outdoor boards (OSB/3 and $\mathrm{OSB} / 4)$ and from the point of tenacity in 
light-load-bearing boards and high-load-bearing boards. OSBs are usually made of three layers: two surface layers with large chips and a core layer with smaller chips. The three layers are symmetrical, although the core layer is thicker, thus ensuring high dimensional stability and balanced strength in the direction parallel to the fibers of the surface chips (in the direction of board length or major axis), and perpendicular to them (in the direction of board width or minor axis). From this last point of view, OSBs are almost similar to plywood; one difference could be thatthe price of OSBs is much lower than plywood, which it successfully replaces today in the construction field.

Some authors [3-5] evaluated the possibility of making OSBs without using the classic strands after obtaining OSBs with an outer layer of chips that is four times smaller than those in current factory technology; they were compared with commercial OSB/3 boards. The results led to the idea that a new standard and category of OSBs can be considered. On the other hand, the air permeability rate, having as variable parameters the board thickness of 12 and $18 \mathrm{~mm}$ and the board type of OSB/3 and $\mathrm{OSB} / 4$, were measured. Test specimens made of OSB $/ 3$ had a low permeability resistance of $61 \%$ for both thicknesses. The possibility of making low-density OSB/3 boards from industrial pine chips was also evaluated. Boards with a minimum density of $425 \mathrm{~kg} / \mathrm{m}^{3}$ were obtained (with a compression coefficient of 0.85 for the analyzed pine species), which had the physical and mechanical properties above those required by EN 300:2006. In 2020, experimental studies on OSB-LVL joints [6], using a 6 $\mathrm{mm}$ thick OSB, were conducted. A simplified 3D nonlinear finite element model was also used to find the behavior of the structure subjected to vertical and lateral loads. Good results using OSBs were obtained. OSBs from balsa wood scraps [7] and the use of an adhesive based on castor oilwas also obtained. The boards obtained with different densities and percentages of adhesive were analyzedby comparison to the standard EN 300:2006. A better compression was confirmed by a density of 650 $\mathrm{kg} / \mathrm{m}^{3}$ and an internal bond of 0.46 MPa. An analysis between OSBs and other composite boards such as Medium Density Fibreboard and classic chipboard [8] was made in order to study its capabilityof use in the furniture and interior decoration industry. Other research $[9,10]$ studied the influence of isocyanine adhesive content on the properties of OSBs treated at high temperatures of 160 and $175^{\circ} \mathrm{C}$. In 2012, other groups of researchers [10] studied the use of OSBs as a substrate in wood flooring, noting that there are minimal distortions in the use of OSBs. Other authors made an ecological OSB [11] from chips of cypress and pine wood and replaced the synthetic adhesive with a mixture of lignin and tannin. The OSB made of cypress chips was more resistant to termite insects, and putrefaction resistance increased with anincrease in the ratio of cypress chips to pine chips. A group managed by Arnould [12] tested an ecological OSB obtained in the laboratory against fungal attack. From the research, an optimum resin-wood combination, from the point of view of biological and mechanical properties, was obtained. Other authors [13] wanted to obtain rigid OSBs to be used in floors. During the research, two types of chips were used: one with $90 \%$ aspen and $10 \%$ birch, and another with $100 \%$ pine. The best boards were those with the aspen-birch mixture, with values of mechanical properties (Modulus of Rupture-MOR, Modulus of Elasticity-MOE, and Internal bond-IB) close to birch veneer plywood. This research has shown that a mixture of two species provides better quality OSBs than single species usage [14]. Two strand boards with low density (aspen) and one with medium density (birch) were compared using strands with three lengths of 78, 105 and $142 \mathrm{~mm}$ and two chip thicknesses of 0.55 and $0.75 \mathrm{~mm}$ [15]. The best strengths (MOR, MOE, compressive strength, and IB) were obtained for birch and long and thin strands, demonstrating that high strengths are obtained from softwood with a low or medium density. The mixture of three chip types (red cedar, eucalyptus, and pine) for OSBswas investigated. Research by this author [16] showed that eucalyptus can replace the more expensive pine wood, but red cedar reduces its mechanical properties. Another group managed by Chiromito [17] evaluated the influence of chip length on OSBs made from Pinus taeda species. The results showed that the obtained board's properties exceeded the requirements of the EN 310:1999 [18] standard, and the increase in the length of the strands positively influenced the properties of the obtained boards. Other authors [19] have investigated the influence of the juvenile wood of Pinus radiata D., the chips being obtained from several 26-year-old trees in Chile. There was a strong influence of strands of 
juvenile wood after exceeding the proportion of $70 \%$, which means it is a challenge to use this type of wood in the composition of OSBs. Del Menezzi and Tomaselli [20] proposed a heat treatment of an OSB of pine chips produced in the laboratory as a method of dimensional stabilization in order to reduce hygroscopicity and eliminate pressing stresses. A heat treatment, similar to the fibreboard defibration procedure, was performed at $250{ }^{\circ} \mathrm{C}$ for three periods of 4,7 , and $10 \mathrm{~min}$, and the results obtained from the research showed that the swelling in thickness, water absorption, and equilibrium humidity was significantly reduced. Dixon and his group [21] found a process for modeling a bamboo OSB from the point of view of the modulus of elasticity on the major and minor axes. Ferro and group [22], as a solution, replaced mature softwood species with juvenile woods and used castor oil-based polyurethaneas an adhesive. All determinations were in accordance with EN 300:2006 [2] and showed higher strengths than the reference ones; the boards made of high-density species showed better physical performance, and the boards made of wood species with higher density, added little by little, had high mechanical properties. The Fabrianto group [23] investigated the influence of three fast-growing tropical species on OSB/1 boards, with a predilection for mechanical properties and dimensional stability. The result was that the boards derived from the combination of high-density species and other species with low density had better dimensional stability than those produced from a single species. De Freitas and his group [24] demonstrated the potential of two low-density tropical species when used in making OSBs, using castor oil polyurethane resin as the adhesive. All the boards obtained were classified in the OSB/4 category (EN 300), namely, boards with high mechanical strength and low hygroscopicity. Han's group [25] investigated the mechanical properties of OSBs made of small-diameter logs of pine and willow containing substantial portions of juvenile wood. The researchers showed that with the increase in chip thinness, the internal bond increased by up to $20 \%$. They investigated the effect of wood species and the orientation of chip layers by creating three types of orientations [26] - perpendicular, parallel and random—and the use of three wood species with anhydrous wood densities of $0.36,0.41$ and $0.46 \mathrm{~g} / \mathrm{cm}^{3}$. OSBs made from lower density wood species had better mechanical properties and high dimensional stability. The boards with a perpendicular middle layer had better properties than the random or parallel ones. Mantanisand his group [27] analyzed the typology of adhesives used in the manufacture of OSBs, their main characteristics being evaluated asthe low emission of formaldehyde and the lower price. There was also an evaluation of the production of OSBs per year at the European level (Figure 1), the top producers being Germany, followed by Poland and Romania [27].

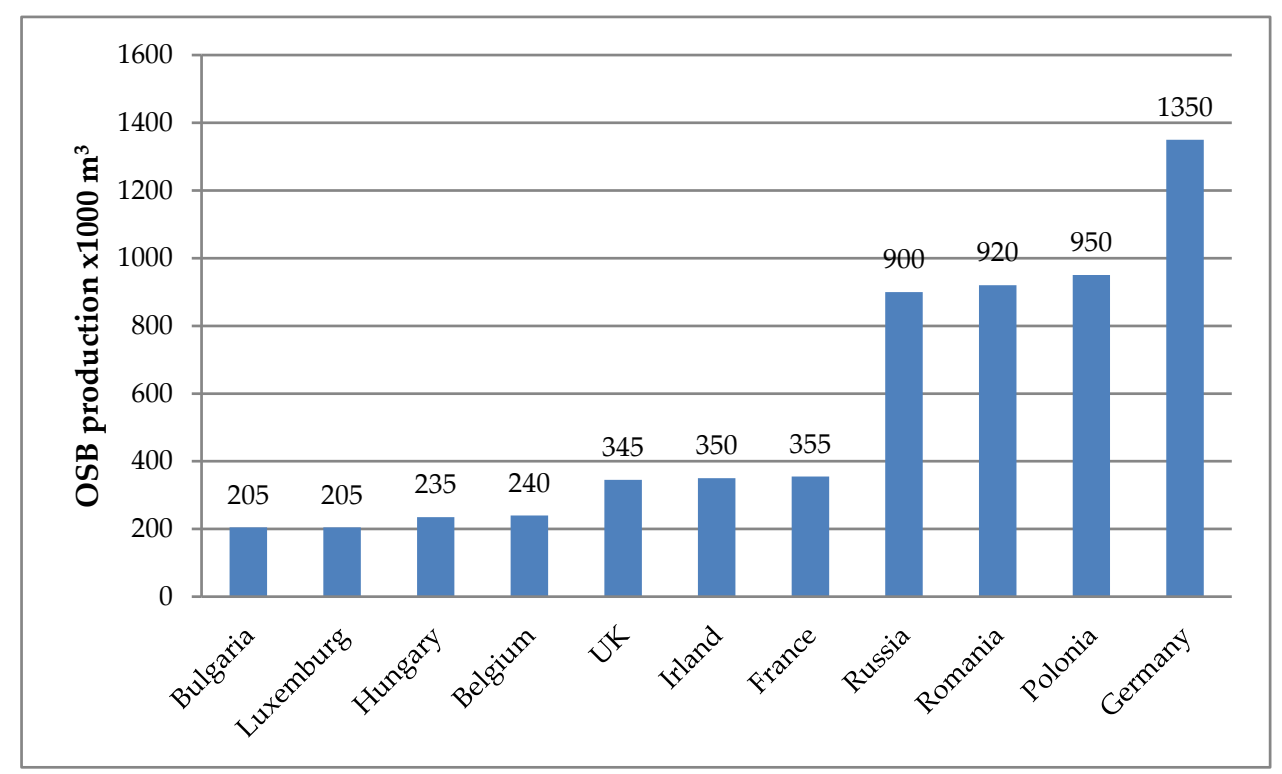

Figure 1. Statistical data compared to the production of oriented strand boards (OSBs). 
Other researchers $[28,29]$ studied the influence of the type of adhesive (urea-formaldehyde (UF) and phenol-formaldehyde (PF)) on the properties of OSBs made of pine. OSBs with PF adhesive on the surfaces and UF adhesive in the core were just as good as those that used only PF adhesive for both surface and core. A similar group evaluated the effect of pretreatment of strand particles and OSBs (post-treatment) on physical and mechanical properties. Heat treatment of large chips led to better dimensional stability and, compared to post-thermal treatment, had a more pronounced effect. The Okino group [30], who evaluated OSB properties of $750 \mathrm{~kg} / \mathrm{m}^{3}$ density made of Brazilian pine wood, with a chip length of $80 \mathrm{~mm}$ and the use of $5 \%$ and $8 \%$ urea-formaldehyde or phenol-formaldehyde resin, found that a higher adhesive content does not produce a significant increase in properties. They also evaluated the effect of high chip-drying temperature on the mechanical properties of OSBs [31]. The results showed that the strength to internal cohesion ratio was higher for dry chips at $150{ }^{\circ} \mathrm{C}$ than at other higher temperatures. Wang and Lam [32] evaluated a regression model of the slenderness ratio of strands and flake orientation to obtain superior characteristics of OSBsin MOE, MOR, IB, and thickness swelling. Other authors [33] investigated the behavior of pine chips on the properties of OSBs. Some impact of hot pressing on the surface layer (higher compression) was observed compared to the core layer.

As a conclusion of the analysis of the specialized articles in the field of the themes, an initiation of solutions to find new sources of raw materials for the production of OSBs, so as to decrease the pressure on softwood species that currently seem to be the basis of good quality raw material, is observed. Additionally, both OSB manufacturers and researchers have reported their work results to the requirements of the European standard EN 300:2006 [2] and chip geometry to factory conditions. Another pertinent conclusion of the bibliographic study is that the mixture of wood species is more advantageous than the use of individual species, and soft species with medium and low densities are most often used in OSB technology. In this sense, the main objective of the paper is to comparatively analyze OSBs obtained from a hardwood mixture andasoftwood mixture obtained under laboratory conditions (but respecting factory technology, including the chips used, the density of the board, and the adhesive type). In this sense, the physical properties (swelling and water absorption, density), as well as the mechanical ones (strength and modulus of elasticity to bending, internal cohesion) of the boards obtained in the laboratory, will be taken into account and compared to the OSB/3 board specifications required by factories.

\section{Materials and Methods}

For experiments, wet hardwood and softwood chips supplied by the Kronospan Trading Romania company, Brasov, Romania [33], were used in the manufacture of OSBs. The place of collection in the manufacturing flow was immediately after cutting them into chips, after a few weeks, thus obtaining a clear differentiation of wood species. Separate softwood chips (fir, spruce, and pine) and separate fast-growing hardwood chips (poplar, willow, and birch) were obtained, with an average geometry of $80 \times 12 \times 0.9 \mathrm{~mm}$ and minor differences from one species to another. The mixture of species was dictated by the properties of future boards, as specified by other authors [14]. The chips were dried under laboratory conditions up to the humidity of $6-8 \%$, after which the hardwood and softwood species were mixed separately, thus obtaining the hardwood and softwood strands. The dried chips were subjected to sorting, after which, according to the factory technology, surface chips (F), core chips (core C), and chips with dimensions smaller than $5 \times 5 \mathrm{~mm}^{2}$ were eliminated. The chips were mixed with aLupranet-type adhesive (currently used by the Kronospan company), respecting the percentage and factory recipe. To obtain repeatability of the mixing conditions of the chips with the adhesive, a mechanical mixer was used, and the materials were weighed in grams on an electronic scale with an accuracy of $0.1 \mathrm{~g}$. The operation was performed very carefully. The required amount of dry chips was calculated, taking into account the thickness of the $12 \mathrm{~mm}$ plate and the format of the press of the final plate. The formation of the chip carpet was performed on a metal support sheet and a forming frame, and, between the sheet and the mat, a heat-resistant foil that did not allow the OSB to stick 
to the support sheet was placed. The mat was three-layered, using the chips corresponding to the layers, such as the percentage of surface and core chips and the perpendicular arrangement of the core layer to the surface layers. The pressing took place at a temperature of $170{ }^{\circ} \mathrm{C}$ and a pressure of $4 \mathrm{MPa}$ for a period of $15 \mathrm{~min}$. The board obtained was an OSB/3 outdoor type, also made by Mirski and Dziurka [3], and it was conditioned for $48 \mathrm{~h}$, after which it was edged, and the test pieces necessary for density, moisture content, static bending on major and minor axes, internal bond, swelling in thickness, and water absorption were created. The characteristics of OSB/3 boards made by the Kronospan Company, Brasov, Romania (OSB/3-Krono) are in accordance with the EN 300 standard (Table 1).

Table 1. Properties of boards with high-load-bearing capacity for the outside (OSB/3-Krono).

\begin{tabular}{cccc}
\hline Items & Properties & Thickness 8-25 $\mathbf{~ m m ~}$ & Standard \\
\hline 1 & Volume mass $\left(\mathrm{kg} / \mathrm{m}^{3}\right)$ & $\geq 620$ & EN 323 \\
2 & Bending strength-major axis (longitudinal) $\left(\mathrm{N} / \mathrm{mm}^{2}\right)$ & $\geq 20$ & EN 310 \\
3 & Bending strength-minor axis (transversal $\left(\mathrm{N} / \mathrm{mm}^{2}\right)$ & $\geq 11$ & EN 310 \\
4 & Modulus of elasticity-longitudinal $\left(\mathrm{N} / \mathrm{mm}^{2}\right)$ & $\geq 4000$ & EN 310 \\
5 & Modulus of elasticity-transversal $\left(\mathrm{N} / \mathrm{mm}^{2}\right)$ & $\geq 1600$ & EN 310 \\
6 & Internal bond $\left(\mathrm{N} / \mathrm{mm}^{2}\right)$ & $\geq 0.35$ & EN 319 \\
7 & Swelling thickness $(24 \mathrm{~h})(\%)$ & $\leq 15$ & EN 317 \\
8 & Moisture content $(\%)$ & $2-12$ & EN 322 \\
9 & Formic aldehyde emission Super Class E0 $(\mathrm{ppm})$ & $<0.03$ & EN 717-1 \\
10 & Internal cohesion after hot water test $\left(\mathrm{N} / \mathrm{mm}^{2}\right)$ & $\geq 0.15$ & EN 1087-1 \\
\hline
\end{tabular}

\subsection{Determination of Chip Moisture Content}

The moisture of the OSBs was determined by the gravimetric method-the method ofweighing-drying-weighing of the prismatic pieces (10 specimens) with the dimensions of 50 $\times 50 \mathrm{~mm}^{2}$. Prior to determination, the boards were conditioned for $48 \mathrm{~h}$ at a relative air humidity of $65 \%$ and a temperature of $20^{\circ} \mathrm{C}$. To determine the moisture, a Memmert drying oven (Germany) and a Kern electronic balance (Germany) were used for weighing the test pieces. Ten parts were weighed for each type of board, with an accuracy of $0.1 \mathrm{~g}$. After that, the test parts were placed in the laboratory oven at $105^{\circ} \mathrm{C}$ for a period of $10 \mathrm{~h}$ in order to dry them until constant mass. During drying, multiple weighings were made, and it was considered that an absolutely dry mass, $\mathrm{m}_{0}$, was obtained when the difference between two successive weightings was insignificant (less than $0.2 \mathrm{~g}$ ). Absolute moisture content (relative to the dry mass of the test piece) was determined as a percentage ratio between the mass of water in the wood and the mass of absolutely dry wood with the following relationship (Equation (1)):

$$
\mathrm{M}_{\mathrm{C}}=\left(\mathrm{m}_{\mathrm{w}}-\mathrm{m}_{0}\right) \div \mathrm{m}_{0} \times 100(\%)
$$

where $\mathrm{M}_{\mathrm{c}}$-moisture content (\%); $\mathrm{m}_{\mathrm{w}}$-wet mass of test parts (g); $\mathrm{m}_{0}$-absolutely dry mass of test parts (g).

\subsection{Determination of Board Density}

The determination of board density, conforming to EN 323:1993 [34], was made as a ratio between the mass and the volume of the test parts with dimensions of $50 \times 50 \mathrm{~mm}^{2}$, after the parts were conditioned. Considering that the test parts had a regular parallelepiped shape, the calculation relationship used to determine the density $(\rho)$ was as follows (Equation (2)):

$$
\rho=\left(\mathrm{m} \times 10^{6}\right) \div\left(\mathrm{l}_{1} \times \mathrm{l}_{2} \times \mathrm{t}\right)\left(\frac{\mathrm{kg}}{\mathrm{m}^{3}}\right)
$$

where $\mathrm{m}$-test piece mass $(\mathrm{g}) ; \mathrm{l}_{1}$-the longitudinal size of the test piece $(\mathrm{mm}) ; \mathrm{l}_{2}$-perpendicular dimension of the test piece $(\mathrm{mm})$; $\mathrm{t}$-the test piece thickness $(\mathrm{mm})$. 


\subsection{Determination of Water Absorption and Swelling of the Boards Conforming to EN 317}

Both determinations were performed at the same time on parallelepiped test parts with a section of $50 \times 50 \mathrm{~mm}^{2}$ [35]. The conditioned pieces were initially weighed, and their thickness measured, after which they were immersed for $24 \mathrm{~h}$, and then the dimensions were weighed and measured again. The calculation relationships used for absorption (A) and swelling (S) were the following (Equation (3)):

$$
A=\left(m_{f}-m_{i}\right) \div m_{i} \times 100[\%] ; S=\left(t_{f}-t_{i}\right) \div t_{i} \times 100(\%)
$$

where $\mathrm{m}_{\mathrm{i}}$-mass of test pieces before immersion $(\mathrm{g}) ; \mathrm{m}_{\mathrm{f}}$-mass of test pieces after immersion in water $(\mathrm{g}) ; \mathrm{t}_{\mathrm{i}}$-initial thickness of test pieces before immersion $(\mathrm{mm}) ; \mathrm{t}_{\mathrm{f}}$ - final thickness of test pieces after immersion in water (mm).

\subsection{Determination of Modulus of Rupture (MOR) and Modulus of Elasticity (MOE) According to EN 310}

Both tests (MOR and MOE) were determined simultaneously on the same universal test machine, an IMAL IB 600 (Italy). For this test, the corresponding devices were attached, respectively, to the two lower supports and the upper die for force application with a diameter of $30 \mathrm{~mm}$ [36]. The MOR and MOE determination relationships used by the test machine software were as follows (Equation (4)):

$$
\begin{gathered}
\text { MOR }=(3 \times \mathrm{P} \times 1) \div\left(2 \times \mathrm{w} \times \mathrm{h}^{2}\right)\left(\frac{\mathrm{N}}{\mathrm{mm}^{2}}\right) ; \\
\mathrm{MOE}=\left(\mathrm{l}^{3} \times\left(\mathrm{P}_{2}-\mathrm{P}_{1}\right)\right) \div\left(4 \times \mathrm{w} \times \mathrm{h}^{3} \times\left(\mathrm{f}_{2}-\mathrm{f}_{1}\right)\right)\left(\frac{\mathrm{N}}{\mathrm{mm}^{2}}\right)
\end{gathered}
$$

where $\mathrm{P}$-the maximum stress $(\mathrm{N})$; 1 - the distance between the supports $(\mathrm{mm})$; $\mathrm{w}$-the width of the cross-section of the test pieces $(\mathrm{mm})$; $\mathrm{h}$-the height of the test piece in the cross-section $(\mathrm{mm}) ; \mathrm{P}_{2}$ - the force corresponding to a percentage of $40 \%$ of the breaking force $(\mathrm{N})$; $\mathrm{P}_{1}$ 一 the force corresponding to a percentage of $10 \%$ of the total breaking force $(\mathrm{N}) ; \mathrm{f}_{2}$-the deformation corresponding to the force of $\mathrm{P}_{2}(\mathrm{~mm}) ; \mathrm{f}_{1}$ - the deformation corresponding to the force of $\mathrm{P}_{1}(\mathrm{~mm})$.

\subsection{Determination of Internal Bond of Boards According to EN 319}

The internal bond is a complex property of boards that depends on the type of adhesive, the size and particle size of the chips, the specific pressure applied to the press, and many other technical and technological elements. Internal bond was performed on $50 \times 50 \mathrm{~mm}^{2}$ test pieces [37], glued on special jaws, on the same universal test machine, an IMAL IB 600. The calculation ratio of this strength (IB) was as follows (Equation (5)):

$$
\mathrm{IB}=\mathrm{P}_{\max } \div 1_{1} \div 1_{2}\left(\frac{\mathrm{N}}{\mathrm{mm}^{2}}\right)
$$

where $\mathrm{P}_{\max }$-maximum breaking force $(\mathrm{N}) ; \mathrm{l}_{1}$ — the size of one side of the test piece $(\mathrm{mm}) ; \mathrm{l}_{2}$ 一the size of the other side of the test piece (mm).

In the study, different types of OSB boardswere analyzed: OSB boards obtained from mixed softwood (pine, fir, and spruce), mixed hardwood (poplar, willow, and birch), and OSB/3 manufactured by Kronospan. The mixture of species is approximately in equal proportions. The analyzed properties of OSB boards were density, swelling (24 h), absorption ( $24 \mathrm{~h}$ ), internal bond (IB), modulus of rupture (MOR), and modulus of elasticity (MOE) on bending strength.

In order to compare the properties of OSB boards, the mean values were considered (displayed by interval plots diagrams). The analyses of the physical and mechanical properties of OSBs were statistically analyzed using Minitab 17 software (Minitab LLC, State College, PA, USA). The analysis consists of comparing the OSBs made of softwood and hardwood mixtures by applying interval plots with a confidence interval $(\mathrm{CI})$ of $95 \%$ in order to underline the differences between the main properties of the OSBs under study. 


\section{Results}

\subsection{Analysis of Physical Properties of OSBs}

The moisture content of the boards, determined in accordance with European standards (EN 322), was around $10 \%$. The density of OSBs made of mixed softwood species was higher than the density of OSBs made of mixed hardwood, although the estimated mean values of the densities were similar for a confidence interval of $95 \%$ : the estimated median values for softwood OSBs were $753.8 \mathrm{~kg} / \mathrm{m}^{3}$ and for mixed hardwood OSBs $719.1 \mathrm{~kg} / \mathrm{m}^{3}$. Similar densities were found by the Barbirato group [7] and Okino [30], with a 0.8-1.0 compression coefficient related to wood species density. Additionally, it can be noticed that the differences between board properties are not statistically significant, and a high variation of density for OSBs made from mixed hardwood is caused by the difference in the analyzed sample sizes. The interval plot of density for each type of analyzed OSBs is plotted in Figure 2.

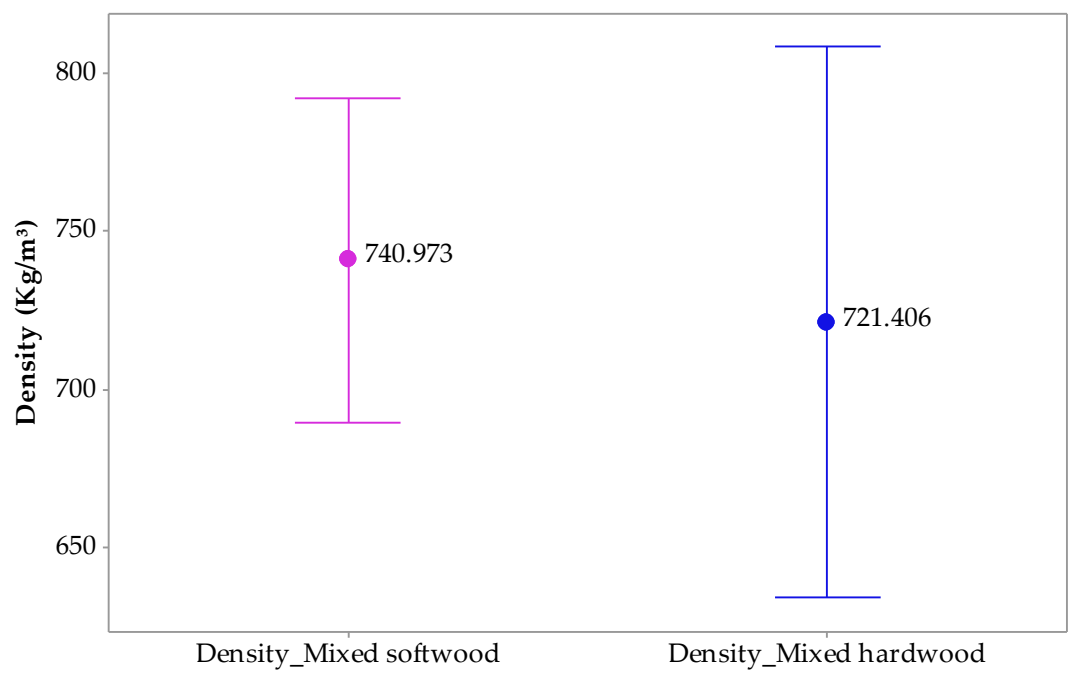

Figure 2. Interval plot of density for the analyzed types of OSBs.

Figure 3 shows that the physical properties of swelling and absorption for softwood OSBs are superior to hardwood boards. In the case of swelling, the values of the estimated means are comparable, but the values of the medians differ. Additionally, extreme values were recorded for OSBs from softwoods (minimum $=2.87 \%$, maximum $=8.62 \%$ ). Although the swelling for OSBs from softwood had a high estimated value of median compared to the OSBs from hardwoods, a large variation of data was observed. In terms of absorption, the estimated values of the means are higher for OSBs made of softwood. For analyzed types of OSBs, the estimated statistical parameters reveal the same trend of data distribution. The analysis of both types of OSBs indicates that the difference is not significant. 


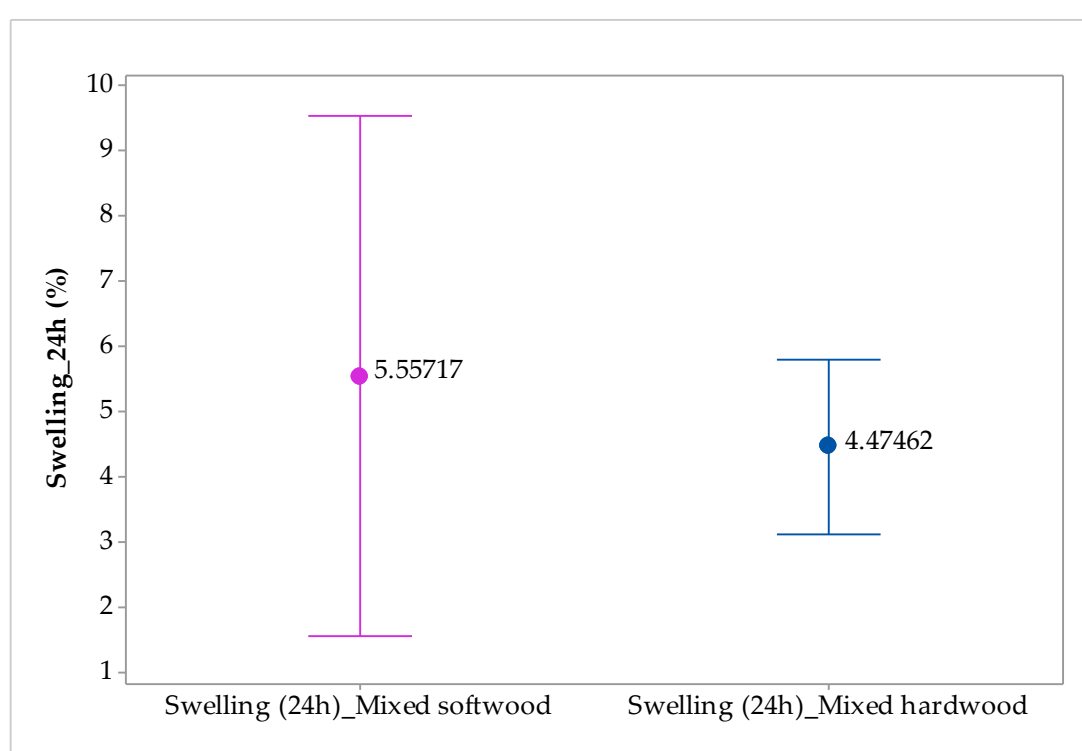

(a)

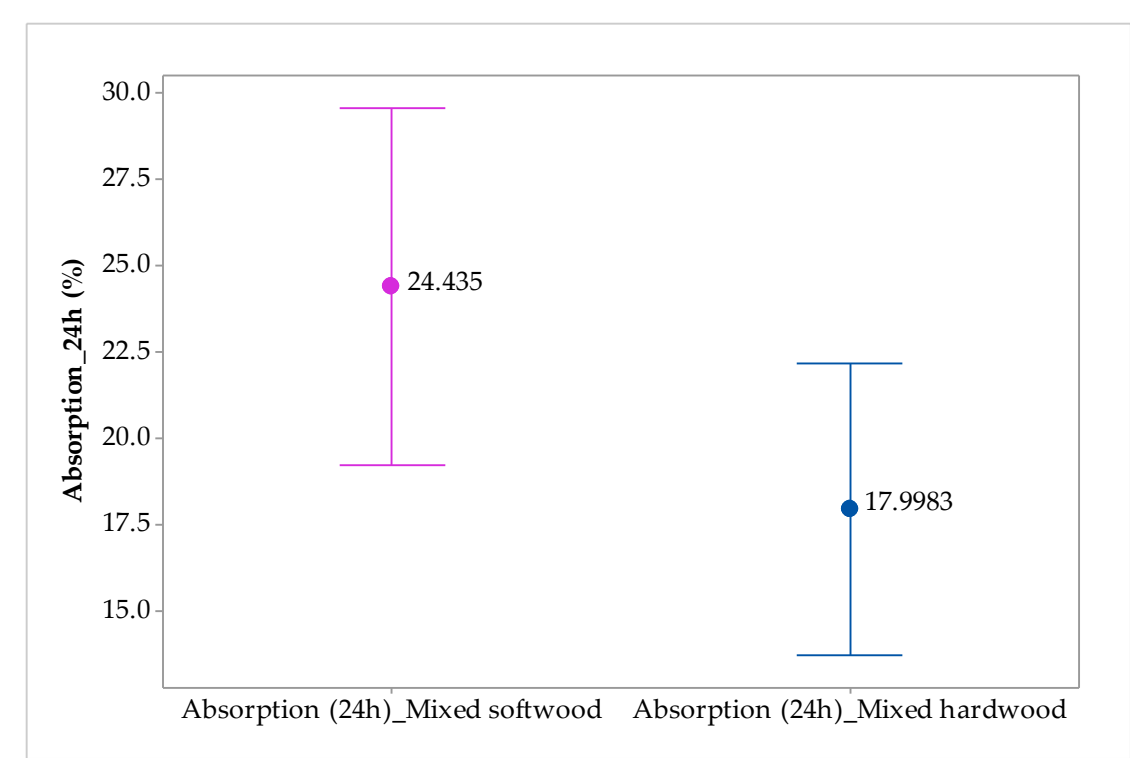

(b)

Figure 3. Interval plot of analyzed properties for OSB types: (a) swelling; (b) absorption.

\subsection{Analysis of Mechanical Properties of OSBS}

A comparative assessment of the MOR and MOE properties of OSBs by the implementation of interval plots with $95 \% \mathrm{CI}$ indicates that the differencesare not significant.

Analyzing the MOR properties, the estimated average value for OSBs from softwoods is $54.50 \mathrm{~N} / \mathrm{mm}^{2}$, with $43.48 \mathrm{~N} / \mathrm{mm}^{2}$ for hardwood OSBs. From the point of view of the estimated median, the difference between them shows that the MOR properties of the softwood OSBs are superior to the MOR properties of the hardwood boards, with a difference of $25.3 \%$. Similar results were obtained by other authors [15]. Additionally, the confidence interval of MOR values for softwood OSBs shows a high variance of data comparing to hardwood OSBs (Figure 4a). 


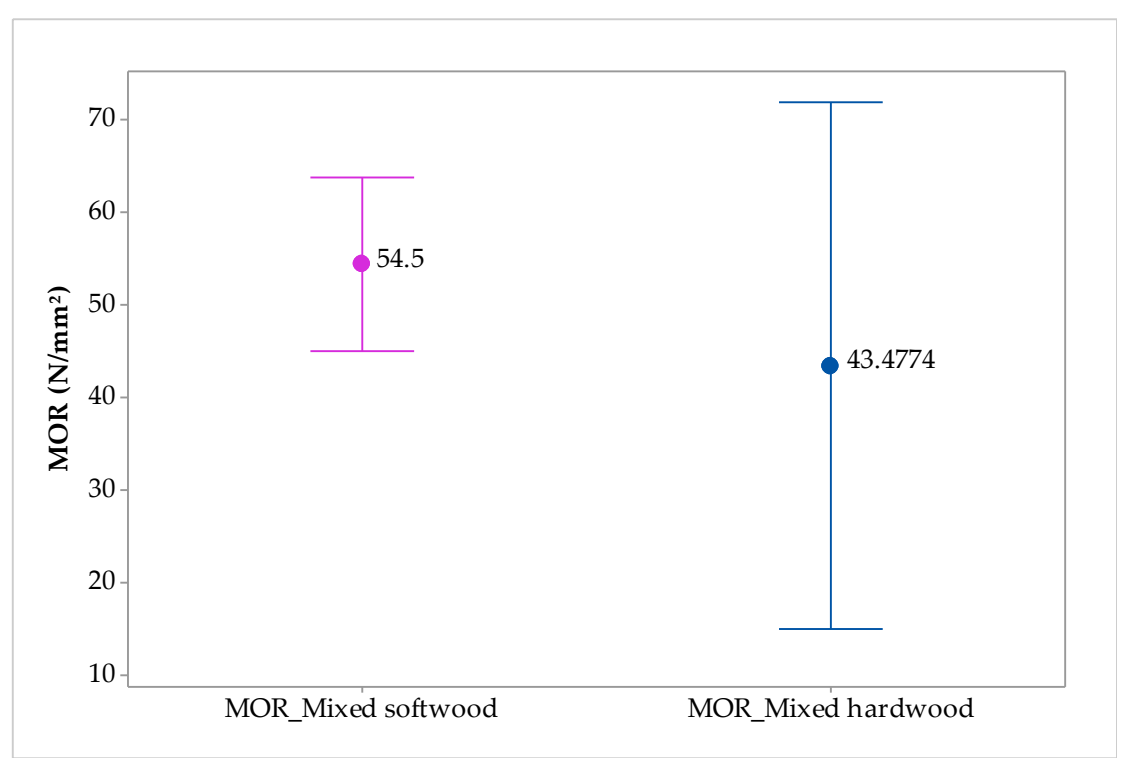

(a)

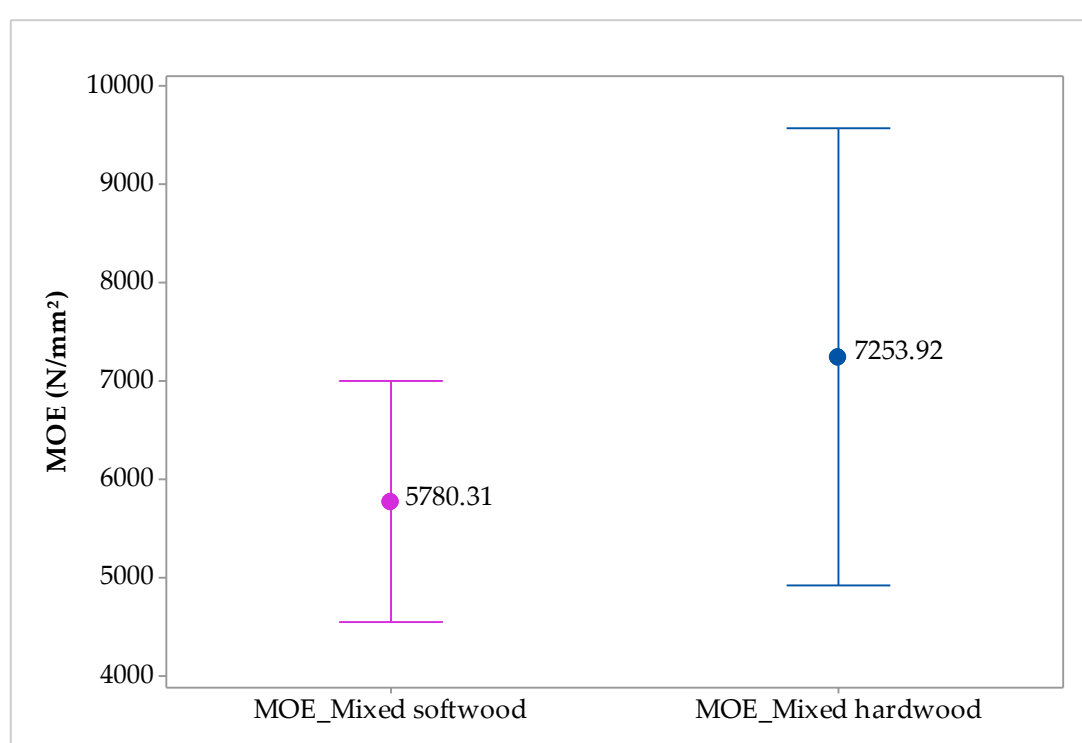

(b)

Figure 4. Interval plot of analyzed properties for OSB types: (a) modulus of rupture (MOR); (b) modulus of elasticity (MOE).

Regarding the MOE properties, the hardwood OSBs present superior MOE values, with a mean of $7253 \mathrm{~N} / \mathrm{mm}^{2}$, while softwood OSBs reveal lower properties $\left(\mathrm{MOE}=5780 \mathrm{~N} / \mathrm{mm}^{2}\right.$ ). This fact is shown by the estimated mean values for the analyzed types of OSBs (Figure $4 \mathrm{~b}$ ).

The comparative analysis of the MOR and MOE properties that are specific to the major and minor axes is presented graphically in Figures 5 and 6 . Analyzing the modulus of rupture, it can be observed that the obtained values exceed the specified value of OSB/3-Krono. Additionally, higher values were obtained for OSBs made of mixed softwood species. 


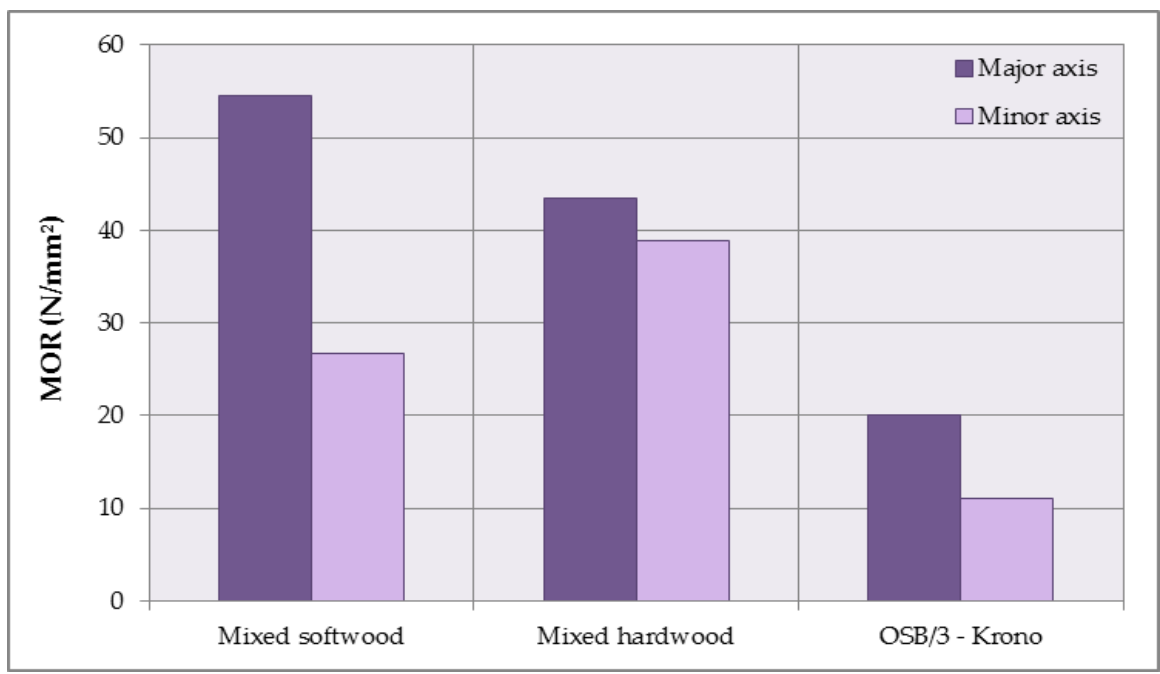

Figure 5. MOR of OSB panels from mixed species compared to OSB/3-Krono.

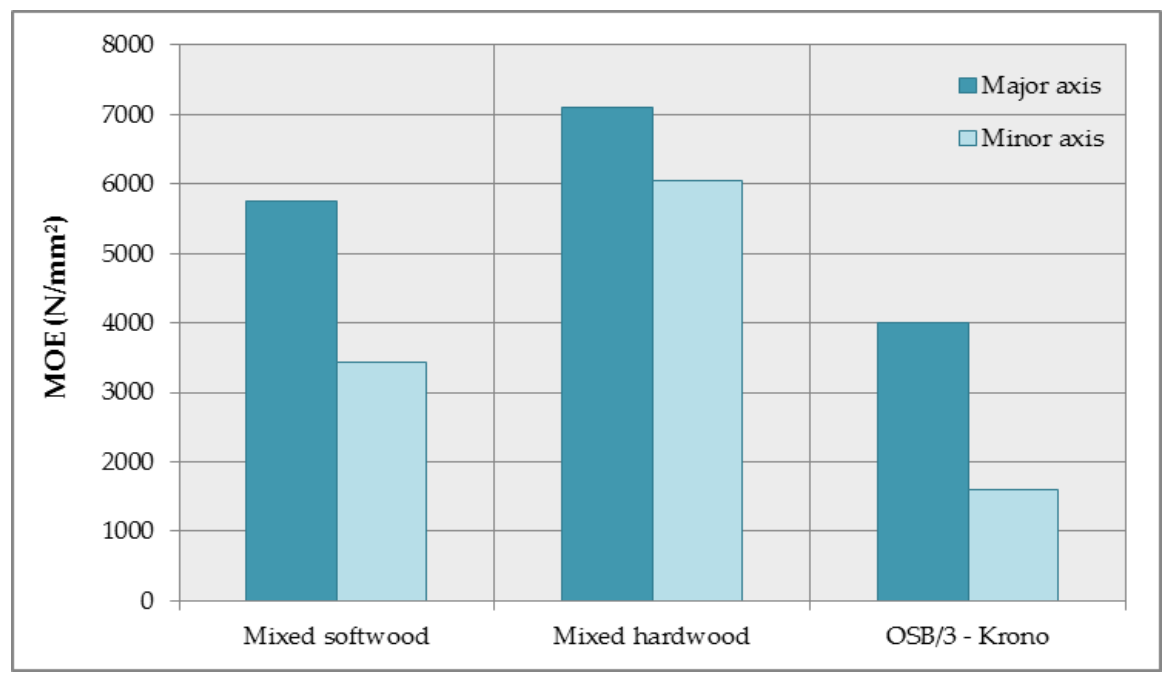

Figure 6. MOE of OSB panels from mixed species compared to OSB/3-Krono.

In the case of the modulus of elasticity of different types of manufactured OSBs, it can be seen that the modulus of elasticity at static bending on the major axis exceeded a value of $4000 \mathrm{~N} / \mathrm{mm}^{2}$, the manufactured board from the mixture of hardwood having the maximum value of $7110 \mathrm{~N} / \mathrm{mm}^{2}$ (Figure 6).

Outdoor OSBs are usually tested by internal bond, both for dry boards and for boards boiled in water for $2 \mathrm{~h}$.The interval plot of internal bond properties for analyzed OSBs indicates that hardwood OSBs display higher IB properties than softwood OSBs. High values of mean $\left(1.57 \mathrm{~N} / \mathrm{mm}^{2}\right)$ and median $\left(1.629 \mathrm{~N} / \mathrm{mm}^{2}\right)$ for IB properties were estimated in the case of mixed hardwood OSBs. Based on the estimated statistical parameter and interval plots with $95 \% \mathrm{CI}$, the analysis indicates that the difference is not significant (Figure 7). 


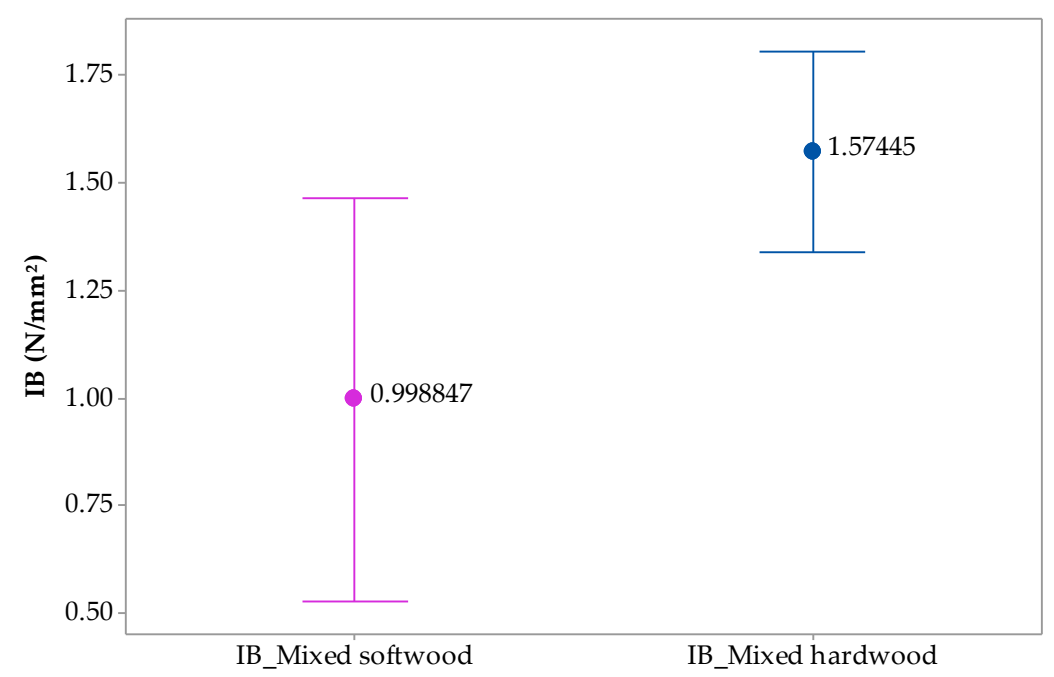

Figure 7. Interval plot of internal bond for the analyzed types of OSBs.

The diminishing strength of the internal bond after boiling in water was different from one group of species to another, as seen in Figure 8. It is observed that the decrease in IB was 38\% for the softwood species mixture and $28 \%$ for the hardwood species mixture. These small differences show that the loss of strength by boiling does not depend on the group of species, but on the adhesive and other hydrophobic substances used. In this paper, the same adhesive recipe was used for all analyzed OSBs, which is why the adhesive factor was removed from the analysis. Additionally, in the case of these determinations, the obtained experimental values exceeded the minimum values of the Kronospan factory (OSB/3), and they are similar to the values obtained by other authors [26].

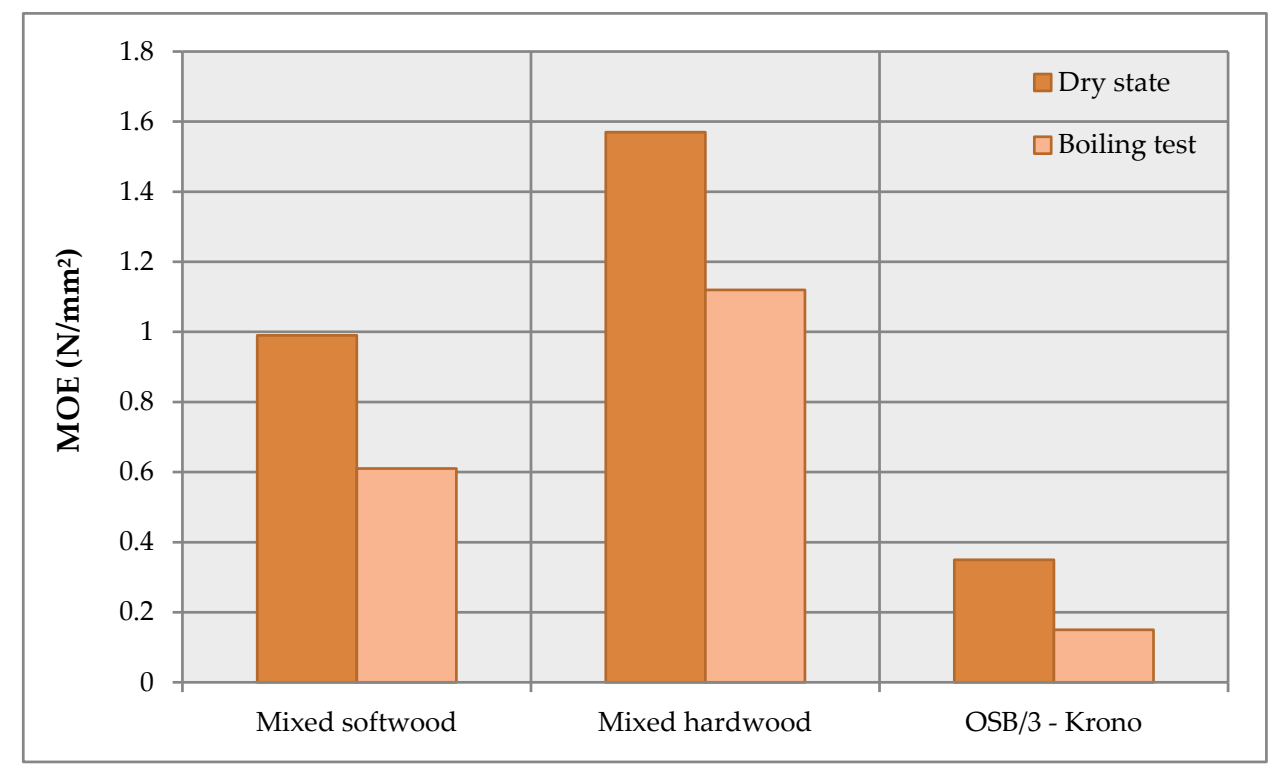

Figure 8. Internal bond of OSB panels from mixed species compared to OSB/3-Krono.

\section{Discussion}

Although some authors $[15,26,27]$ have established that pine wood (or softwoods, in general) is the most used species in the OSB industry, through the experiments performed in this paper, it was found that the mixture of some fast-growing species has properties as good as those of softwoods, sometimes even better than them. This is explained by the fact that fast-growing species are soft species with a medium density, and their mixture leads to superior chip compaction within the OSB. These species approach a structure with the juvenile wood of some woody species, such as eucalyptus [16]. In the 
same sense, some authors [10] have shown that the mixture of aspen and birch creates much stronger boards than pine, and other authors [23] have observed that boards obtained from a mixture of species are more dimensionally stable than those obtained from a single wood species.

The density of OSBs in this work was $740 \mathrm{~kg} / \mathrm{m}^{3}$ for the softwood mix and $714 \mathrm{~kg} / \mathrm{m}^{3}$ for the hardwood mix, noting that at the same pressure, the hardwoods are less compressible by about $3.5 \%$. These values are comparable to those found by other authors [30], with $750 \mathrm{~kg} / \mathrm{m}^{3}$ for pine OSBs or 650 $\mathrm{kg} / \mathrm{m}^{3}$ for balsa wood [7]. Absorption and swelling are up to $36 \%$ and $25 \%$ better in the hardwood mix than in the softwood mix, respectively. Regarding the resistance module, the OSBs resulting from softwoods are up to $25.5 \%$ better than those obtained from the hardwood mix, but the homogeneity of the resistance (obtained by the difference between the resistance on the major and minor axes) is much better in the case of the hardwood mix $\left(4 \mathrm{~N} / \mathrm{mm}^{2}\right)$ than the softwood mix $\left(27 \mathrm{~N} / \mathrm{mm}^{2}\right)$.

One of the major problems of the chipboard industry is that an increase in the density of the boards will cause the mechanical properties of the boards to increase accordingly. Therefore, an analysis of the correlation of mechanical properties with board density was considered appropriate. The influence of density on the physical and mechanical properties of OSB panels is presented in Figure 9. Multiple comparisons of measured properties were made, and the applied method is Dunnett's, which allows us to determine the confidence levels for each individual comparison.

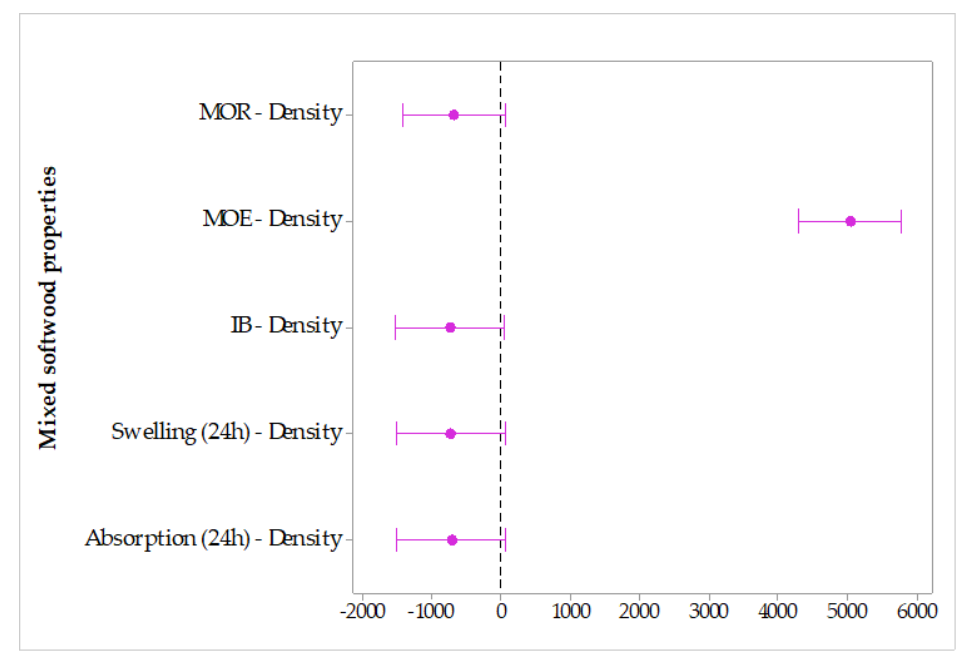

(a)

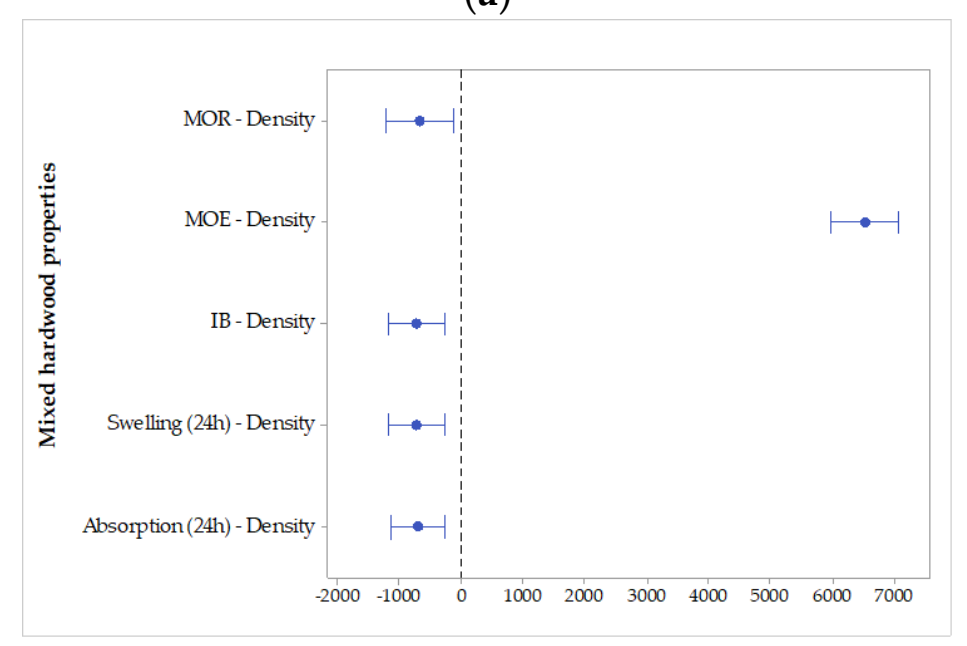

(b)

Figure 9. Comparative analysis of OSB panel properties from mixed species of softwood (a) and hardwood (b). 
The analysis indicates that the density is highly significant in determining MOE values of OSBs manufactured from both mixed species. This can be explained by the fact that the elasticity of the boards is also dependent on other factors (wood elasticity, adhesive content, chip length) than the strength and thickness properties [38]. When the strength is higher, the modulus of elasticity is lower. For the other analyzed properties, there is no significant difference. Similar results indicate that MOR, MOE, IB, and WA were well correlated with board density, whereas the relationship between TS and density was less certain.

As a general conclusion of the whole work, it can be mentioned that the mixture of hardwood species has similar properties to those of the softwood mixture and is, with regards to the mechanical properties, a little better than them. This makes it possible to use these hardwood species in large quantities in the case of the raw material recipe that is used in the current conditions at Kronospan Brasov (over the percentage of 5-8\%). Additionally, less expensive alternative solutions can be found [15], adopting the gradual or total replacement of softwood species with a mixture of fast-growing hardwoods, thus reducing the pressure currently exerted on softwood species.

\section{Conclusions}

1 The characteristics of OSBs obtained in laboratory conditions from mixed species of softwood or hardwood showed very good values, above those required by the standards in the field (EN 300) and higher compared to those required in the manufacturing flow.

2 Analyzing the estimated statistical parameters in the case of swelling and absorption properties after immersion in water for $24 \mathrm{~h}$ for OSBs obtained in the laboratory, it can be concluded that softwood boards are slightly superior to hardwood OSBs.

3 The statistical comparative analysis indicated that fast-growing species exhibited superior mechanical properties (MOR, MOE, and IB) compared to mixed softwood species.

4 The general conclusion of the paper is that the hardwood mixture can be used in large proportions in the OSB recipe without significantly diminishing the properties of the boards, but with favorable effects on raw material costs, also reducing the pressure on the acquisition and consumption of softwood species.

Author Contributions: Conceptualization, A.L. and V.-D.C.; methodology, A.L.; software, A.-E.D.; validation, A.L., A.-E.D., and V.-D.C.; formal analysis, A.-E.D.; investigation, A.L.; resources, V.-D.C.; data curation, A.-E.D.; writing - original draft preparation, A.L.; writing — review and editing, A.-E.D.; visualization, A.-E.D.; supervision, A.L.; project administration, V.-D.C.; funding acquisition, A.-E.D. All authors have read and agreed to the published version of the manuscript.

Funding: This research received no external funding.

Acknowledgments: The authors are grateful to Kronospan Trading Brasov Company for its support in the development of laboratory tests and for providing technical assistance, especially to Iancu Bogdan and Mastan Aurelian. We would also like to thank Transilvania University of Brasov for financial support.

Conflicts of Interest: The authors declare no conflict of interest.

\section{References}

1. ISO. Wood-Based Panel_Oriented Strand Board (OSB)_Definitions, Classification, Specifications; ISO 16864; International Organisation for Standardization: Geneva, Switzerland, 2016.

2. European Committee for Standardisation. Oriented Strand Boards (OSB)_Definitions, Classification and Specifications; EN 300; European Committee for Standardisation: Brussels, Belgium, 2006.

3. Mirski, R.; Dziurka, D.; Derkowski, A. Properties of oriented strandboards with externalla yers made of non-strand chips. BioRes 2016, 11, 8344-8354. [CrossRef]

4. Hodoušek, M.; Böhm, M.; Lemaster, R.L.; Bureš, M.; Beránková, J.; Cvach, J. Air permeation rate of oriented strand boards (OSB/3andOSB/4). BioRes 2015, 10, 1137-1148.

5. Mirski, R.; Dziurka, D. Low-density oriented strandboard. BioRes 2015, 10, 6388-6394. [CrossRef] 
6. Hassanieh, A.; Valipour, H. Experimental and numerical study of OSB sheathed-LVL studwall with stapled connections. Constr. Build. Mater. 2020, 233, 117373. [CrossRef]

7. Barbirato, G.; Fiorelli, J.; Mejia, J.; Sarasini, F.; Ferrante, L. Quasi-static and dynamic response of oriented strand boards based on balsa wood waste. Compos. Struct. 2019, 219, 83-89. [CrossRef]

8. Rebollar, M.; Pérez, R.; Vidal, R. Comparison between oriented strandboards and otherwood-based panels for the manufacture of furniture. Mater. Des. 2007, 28, 882-888. [CrossRef]

9. Direske, M.; Bonigut, J.; Wenderdel, C.; Scheiding, W.; Krug, D. Effects of MDI content on properties of thermally treated oriented strandboard (OSB). Eur. J. Wood Prod. 2018, 76, 823-831. [CrossRef]

10. Barbuta, C.; Blanchet, P.; Cloutier, A.; Yadama, V.; Lowell, E. OSB as substrate for engineered wood flooring. Eur. J. Wood Prod. 2012, 70, 37-43. [CrossRef]

11. Amusant, N.; Arnould, O.; Pizzi, A.; Depres, A.; Mansouris, R.H.; Bardet, S.; Baudassé, C. Biological properties of an OSB eco-product manufactured from a mixture of durable and non durable species and natural resins. Eur. J. Wood Prod. 2009, 67, 439-447. [CrossRef]

12. Arnould, O.; Sturzenbecher, R.; Bardet, S.; Hofstetter, K.; Guibal, D.; De Borst, K.; Nadine, A.; Pizzi, A.P. Mechanical potential of eco-OSB produced from durable and non durable species and natural resins. Holzforschung 2010, 64, 791-798. [CrossRef]

13. Barbuta, C.; Cloutier, A.; Blanchet, P.; Yadama, V.; Lowell, E. Tailor made OSB for special application. Eur. J. Wood Prod. 2011, 69, 511-519. [CrossRef]

14. Akrami, A.; Barbu, M.C.; Fruhwald, A. European hardwoods for reducing dependence on pine for oriented strandboard. Int. Wood Prod. J. 2014, 5, 133-135. [CrossRef]

15. Beck, K.; Cloutier, A.; Salenikovich, A.; Beauregard, R. Effect of strand geometry and wood species onstrand board mechanical properties. Wood Fiber Sci. 2009, 41, 267-278.

16. Bufalino, L. Alternative compositions of Oriented Strand Boards (OSB) made with commercial woods produced in Brazil. Maderas Cienc. Technol. 2015, 17, 105-116. [CrossRef]

17. Chiromito, E.M.S.; Campos, C.I.; Ferreira, B.S.; Christoforo, A.L.; Lahr, F.A.R. Mechanical properties of wood panels produced with wood strands with three different lengths. Sci. For. 2016, 44, 175-180.

18. European Committee for Standardization. Wood-Based Panels: Determination of Modulus of Elasticity in Bending and of Bending Strength; EN 310; European Committee for Standardization: Brussels, Belgium, 1999.

19. Cloutier, A.; Ananias, R.A.; Ballerini, A.; Pecho, R. Effect of radiate pine juvenile wood on the physical and mechanical properties of oriented strandboard. Holz Roh Werks. 2007, 65, 157-162. [CrossRef]

20. DelMenezzi, C.H.S.; Tomaselli, I. Contact thermal post-treatment of oriented strandboard to improve dimensional stability: A preliminary study. Holz Roh Werks. 2006, 64, 212-217. [CrossRef]

21. Dixon, P.G.; Malek, S.; Semple, K.E.; Zhang, P.K.; Smith, G.D.; Gibson, L.J. Multi scale modeling of moso bamboo oriented strand board. BioRes 2017, 12, 3166-3181. [CrossRef]

22. Ferro, F.S.; Souza, A.M.; de Araujo, I.I.; Van Der Neutde Almeida, M.M.; Christoforo, A.L.; Rocco Lahr, F.A. Effect of alternative wood species and first thinning wood on oriented strandboard performance. Adv. Mater. Sci. Eng. 2018. [CrossRef]

23. Febrianto, F.; Hidayat, W.; Samosir, T.P.; Lin, H.C.; Soong, H.D. Effect of strand combination on dimensional stability and mechanical properties of oriented strandboard made from tropical fastgrowing treespecies. J. Biol. Sci. 2010, 10, 267-272.

24. DeFreitas, J.F.; de Souza, A.M.; Granco, L.A.M.N.; Chahud, E.; Christoforo, A.L.; Lahr, F.A.R. Production of structural OSB with cajueiro (Anacardium sp.) and a mescal (Trattinikia sp.) -APreliminaryStudy. Int. J. Mater. Eng. 2017, 7, 17-20.

25. Han, G.; Wu, Q.; Lu, J.Z. Selected properties of wood strand and oriented strand board from small-diameter southern pine trees. Wood Fiber Sci. 2006, 38, 621-632.

26. Hidayat, W.; Sya'bani, M.; Purwawangsa, H.; Hiswanto, A.; Febrianto, F. Effect of wood species and layer structure on physical and mechanical properties of strand board. J. Trop. Wood Sci. Technol. 2011, 9, 134-140.

27. Mendes, R.F.; Mendes, L.M.; Carvalho, A.G.; Silva, A.F.A.; Guimarães, J.B. Effect of laminate inclusion and the type of adhesive in the properties of OSB panels of the wood from Pinus oocarpa. Brazil. J. Wood Sci. 2012, 3, 116-127.

28. Mendes, R.F.; Bortoletto, J.R.G.; Almeida, N.F.; Surdi, P.G.; Barbeiro, I.N. Effect of thermal treatment on properties of OSB Panels. Wood Sci.Technol. 2013, 47, 243-256. [CrossRef] 
29. Mantanis, G.I.; Athanassiadou, E.; Barbu, M.C.; Wijnendaele, K. Adhesive systems used in the European particleboard, MDF and OSB industries. Wood Mater. Sci. Eng. 2018, 13, 104-116. [CrossRef]

30. Okino, E.Y.A.; Teixeira, D.E.; Souza, M.R.; de Santana, M.A.E.; Sousa, M.E. Properties of oriented strandboard made of wood species from Brazilian planted forests: Part 1: $80 \mathrm{~mm}$-long strands of Pinus taeda, L. Holz Roh Werks. 2004, 62, 221-224. [CrossRef]

31. Plagemann, W.; Price, E.W.; Johns, W.E. The response of hardwood flakes and flakeboard to high temperature drying. J Adhes. 2006, 16, 311-338. [CrossRef]

32. Wang, K.Y.; Lam, F. Quadratic RSM models of processing parameters fort three-layer oriented flakeboards. Wood Fiber Sci. 1999, 31, 173-186.

33. Kronospan Trading. Available online: https://ro.kronospan-express.com/ro (accessed on 20 August 2016).

34. European Committee for Standardisation. Wood-Based Panels-Determination of Density; EN 323; European Committee for Standardization: Brussels, Belgium, 1993.

35. European Committee for Standardisation. Particleboards and Fibreboards. Determination of Swelling in Thickness after Immersion in Water; EN 317; European Committee for Standardization: Brussels, Belgium, 1993.

36. European Committee for Standardisation. Particleboards and Fibreboards-Determination of Tensile Strength Perpendicular to the Plane of the Board; EN 319; European Committee for Standardization: Brussels, Belgium, 1993.

37. Wu, Q.Z.; Lee, J.N. Tensile and dimensional properties of wood strands made from plantation southern pine lumber. For. Prod. J. 2005, 52, 1-6.

38. Chen, S.; Du, C.; Wellwood, R. Effect of panel density on major properties of oriented strandboard. Wood Fiber Sci. 2010, 42, 177-184.

(C) 2020 by the authors. Licensee MDPI, Basel, Switzerland. This article is an open access article distributed under the terms and conditions of the Creative Commons Attribution (CC BY) license (http://creativecommons.org/licenses/by/4.0/). 